\title{
An integrated intelligent system for managing the efficiency of the production processes
}

\author{
Victor Kataev ${ }^{1}$ and Ilia Markvo ${ }^{*}$ \\ ${ }^{1}$ Don State Technical University, 1, Gagarina sq., 344003, Rostov-on-Don, Russia
}

\begin{abstract}
Most agricultural enterprises in the Rostov region of the Russian Federation operate the mechanization equipment that differs significantly in terms of the duration of operation and operating time. Significant differentiation of the agricultural machines in terms of service life, operating time and, as a result, reliability leads to the fact that the efficiency of the functioning of the machines is potentially not the same. With non-optimal planning of the production processes in the crop production, certain losses are possible which are associated with delaying the time of work due to the low reliability of the machines, or, on the contrary, a decrease in the efficiency of using mechanization tools with high reliability rates. The consequences of the unsuccessful management decisions are most acutely manifested in the implementation of the harvesting processes, therefore, the aspects of managing the efficiency of the grain crops harvesting processes are considered in the work. The main means of the mechanization during grain harvesting is the combine harvester. Attention is focused on the use of the modern intelligent technologies for managing the production processes in the crop cultivation under the conditions of uncertainty in the environment.
\end{abstract}

\section{Introduction}

The age and technical characteristics of the combine harvesters used in the agricultural enterprises are very heterogeneous, which is not always taken into account when planning the harvesting processes. Updating the machine and tractor fleet will increase the productivity of the agricultural production, but it requires significant capital investments, which may not be economically justified and cannot be implemented simultaneously for all the machines.

The decisions on the reasonability of operation and the need to update the combine fleet, as well as other decisions on the management of the harvesting processes should be based on an assessment of the efficiency of the production processes. The starting point for strategic planning in this area should be a comparison of the effectiveness of the harvesting processes and the costs of their implementation.

The combine harvester is not the only machine used in the cultivation of the grain crops. When harvesting, a complex of the transport machines is used, and the interaction of the

\footnotetext{
*Corresponding author: iluhan markvo@mail.ru
} 
harvesting and transport subsystems has no less impact on the productivity of the harvesting processes.

The analysis of the factors affecting the efficiency of the harvesting processes allows identifying the following groups of the reasons for its decrease [1-3]:

- decrease in the performance due to the technical condition of the machines;

- decrease in the efficiency due to the technological setting and adjustment of the machines and processes;

- decrease in the performance for the organizational reasons;

- decrease in the performance due to the weather (climatic) conditions.

The enlarged structure of the reasons for the decrease in the effectiveness of the processes of harvesting of the grain crops is shown in figure 1 [3].

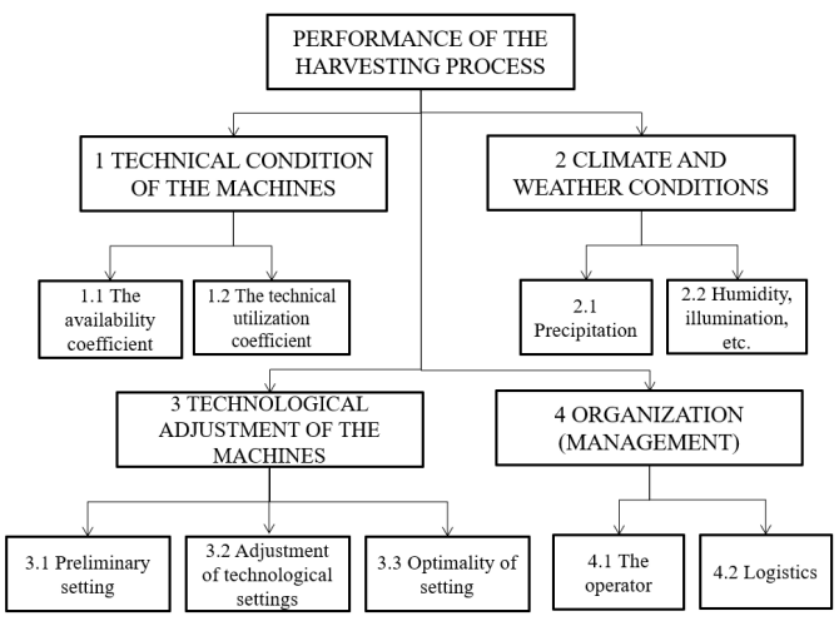

Fig. 1. The reasons for the decrease in the effectiveness of the processes of combine harvesting of the grain crops.

\section{Research status and work relevance}

According to the data of the Federal State Statistics Service of the Russian Federation and [4-8], the agricultural enterprises in Russia (excluding micro-enterprises) operate more than 55 thousand units of the grain harvesters.

The analysis over the past five years has shown a trend towards a decrease in the number of the grain harvesters on the farms (figure 2).

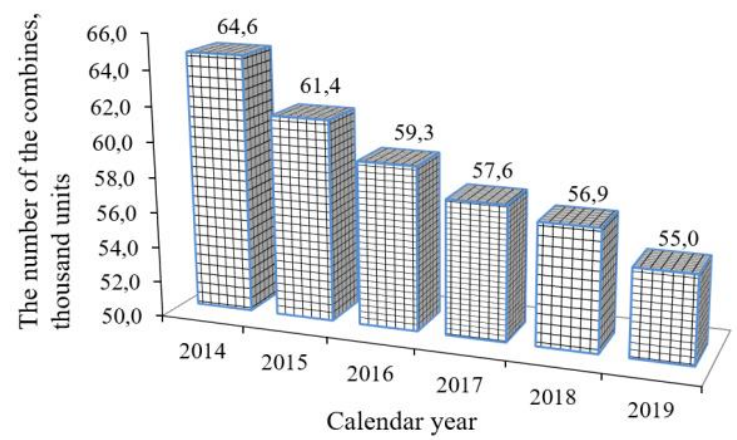

Fig. 2. The number of the combine harvesters operated in the agricultural organizations (excluding micro-enterprises) in Russia. 
According to the Federal State Statistics Service and [9-12], the number of the sown areas, yield and gross harvest of the grain crops show the dynamics that clearly does not correlate with the number of the combine harvesters (figures 3-5).

So the volume of the sown areas for the grain crops does not reach the level which was five years ago (figure 3 ).

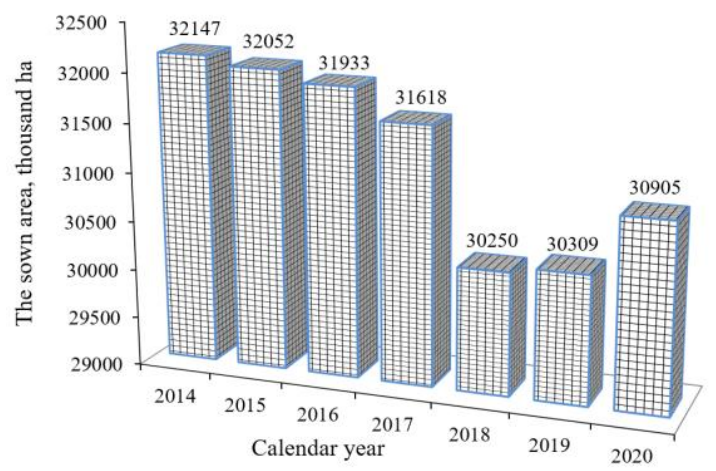

Fig. 3. The number of the sown areas for the grain and leguminous crops in Russia.

However, the yield (figure 4) and gross yield (figure 5) of cereals and the leguminous crops tend to increase.

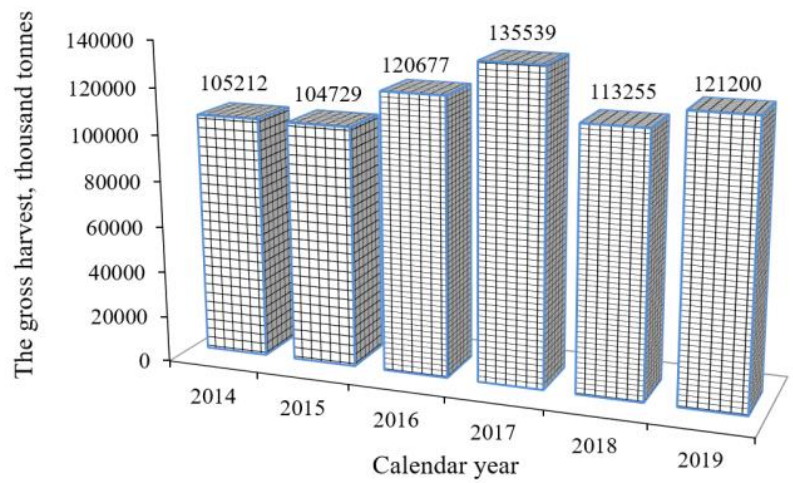

Fig. 4. The gross harvest of the grain and leguminous crops in Russia.

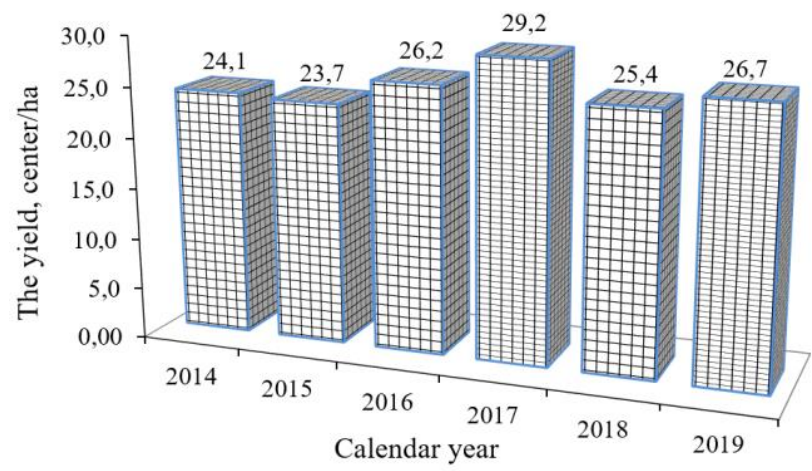

Fig. 5. The yield of the grain and leguminous crops in Russia.

Such an imbalance between the number of the grain harvesters and gross harvests indicates an increase in the seasonal load on a unit of the equipment. 
The compliance with the agrotechnical requirements for the quality and time of harvesting creates demands for high reliability and productivity of the combines. This requires taking into account the characteristics of each specific machine and the individual characteristics of the process management in the organization.

In the Rostov region, the agricultural enterprises and peasant farms operate 4313 (table 1) units of the grain harvesters (as of the end of 2019) [1,2] of different age categories (figure 6) [3].
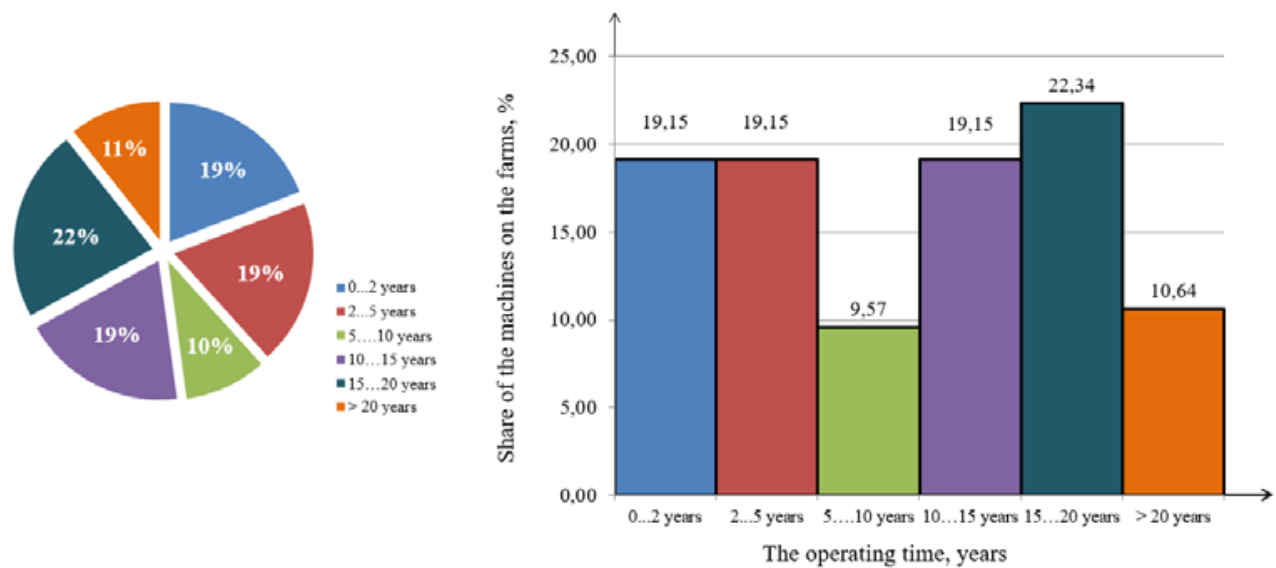

Fig. 6. The distribution of the combine harvesters in the Rostov region by service life.

The combine harvesters are mainly represented by the machines manufactured by Rostselmash (Acros, Vector, Torum, Don 1500).

The harvester fleet is heterogeneous both in terms of the productivity classes and in terms of the technical condition and operating time. With an increase in the operating time of the machines, the values of the technical characteristics decrease, and this leads to a significant difference between the work quality indicators of the combine harvesters, declared by the manufacturer, and the actual indicators.

According to the data of the Federal State Statistics Service of the Russian Federation, in various regions of Russia there are about $2 \ldots 4$ combine harvesters per 1000 hectares, sown with the corresponding crops. The seasonal load on the grain harvester is on average from 200 to 600 hectares.

Table 1. The machinery equipment of the agricultural enterprises of the Rostov region according to the Rosstatistics data.

\begin{tabular}{|l|c|c|c|c|}
\hline \multicolumn{1}{|c|}{$\begin{array}{c}\text { Type of the } \\
\text { equipment }\end{array}$} & $\begin{array}{c}\text { Availability of the } \\
\text { equipment in the } \\
\text { organizations, } \\
\text { units }\end{array}$ & $\mathbf{2 0 1 9}$ in \% by 2018 & $\begin{array}{c}\text { Purchased in a } \\
\text { year, units }\end{array}$ & $\begin{array}{c}\text { Renewal } \\
\text { rate, \% }\end{array}$ \\
\hline Tractors & 10726 & 93.3 & 303 & 2.8 \\
\hline Milking machines & 295 & 94.6 & 12 & 4.1 \\
\hline $\begin{array}{l}\text { Sprinklers and } \\
\text { watering machines }\end{array}$ & 577 & 97.8 & 36 & 7.9 \\
\hline Beet harvesters & 295 & 94.6 & 12 & 4.1 \\
\hline $\begin{array}{l}\text { Combines: } \\
\text { grain harvesters } \\
\text { corn harvesters } \\
\text { potato harvesters }\end{array}$ & 4313 & 93.8 & 201 & 4.7 \\
\hline
\end{tabular}

The machinery supply, the technical condition of the machines, human resources, the sizes of the cultivated areas, the economic and technological capabilities of different agricultural 
producers differ significantly. In such conditions, it is necessary to justify the optimal level of the costs for the harvesting process while achieving the maximum possible work results.

This justification is closely related to the study of the factors affecting the efficiency of the agricultural production and should serve as the basis for developing a strategy for managing the harvesting processes, as well as for achieving the maximum efficiency at given levels of the costs.

When planning the processes of mechanized harvesting of the grain crops, the time of harvesting plays a decisive role. So, according to [13], direct natural losses of grain, depending on the time of the harvest, are determined by the ratio

$$
Y_{g}=1,6 t-4,
$$

where $Y_{g}$ - the grain loss, $\%$ of the yield;

$t$ - the time the grain is in the uncut spike after $3 \ldots 4$ days of full ripeness $(3<\mathrm{t}<25)$.

The authors of [14] conducted a study of the dependence of the crop losses on the excess of the optimal harvesting time and found that the losses in dry years are increased in comparison with moderately wet years. For example, for winter wheat the models for the dependence of the crop losses on the time of harvesting in dry years were obtained in [5].

$$
Y_{g}=0,09 t^{2}-0,71 t+1,53
$$

And in moderate humidity years

$$
Y_{g}=0,07 t^{2}-0,64 t+1,49
$$

It was also established in [14] that for different crops the dependence of the yield losses on the violations of the harvesting time is not the same, but in any case it is direct.

Thus, minimizing the time of harvesting significantly reduces the natural loss of grain by shedding (figure 7). However, reducing the harvest time requires an increase in the shift productivity or a decrease in the seasonal load on the combine harvesters and crop transportation means.

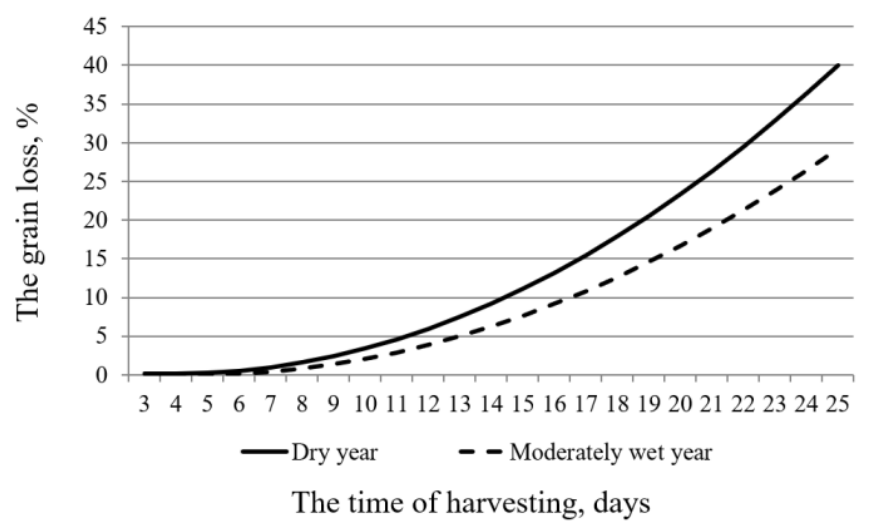

Fig. 7. The dependence of the natural grain loss by shedding on the time of harvesting.

It should be considered that every day from the beginning of the harvesting process (the state of full ripeness of grain) the volume of the unmown crops is reduced by the amount of the shift performance of all the machines.

$$
S_{u . c .}(t)=S_{c r}-\sum_{i=1}^{N} \mathrm{P}_{a i} \times t,
$$

where $S_{\text {u.c. }}$ - the area of the unmown crops;

$S_{c r}$ - the total area under the crops; 
$N$ - the number of the combine harvesters;

$\mathrm{P}_{a i}$ - the actual efficiency of the combine harvesting for the i-th combine.

Then the amount of unharvested crop on the day of the harvest $t$ in the units of mass is determined by the ratio

$$
\mathrm{q}_{\mathrm{e}}(t)=S_{\text {u.c. }}(t) \times \mathrm{y}(t, f),
$$

where $\mathrm{Y}(\mathrm{t}, \mathrm{f})$ - the yield on individual fields depending on the time of harvesting, centner/ha.

The non-cut crops are prone to shedding and drying out, therefore, the yield of the grain crops changes not only depending on the characteristics of the field itself and the growing conditions of the plants, but also on the natural loss of the yield, which grows every day in the uncut spike.

$$
\mathrm{y}(\mathrm{t})=\mathrm{y}_{0}-Y_{g}(t)
$$

where $\mathrm{y}_{0}$ - the initial yield in the selected field (determined on the first day of full ripeness);

$Y_{g}(t)$ - the grain loss as a percentage of the yield, depending on the time the crop remains in the uncut spike.

The studies carried out by us in [1-3] allowed making an assumption about the nature of the dependence between the natural yield losses and the time of harvesting, taking into account the reduction of the unharvested area. Also, a forecast of changes in the costs on ensuring the harvesting process when trying to reduce the harvesting time by engaging additional grain harvesters was made (figure 8).

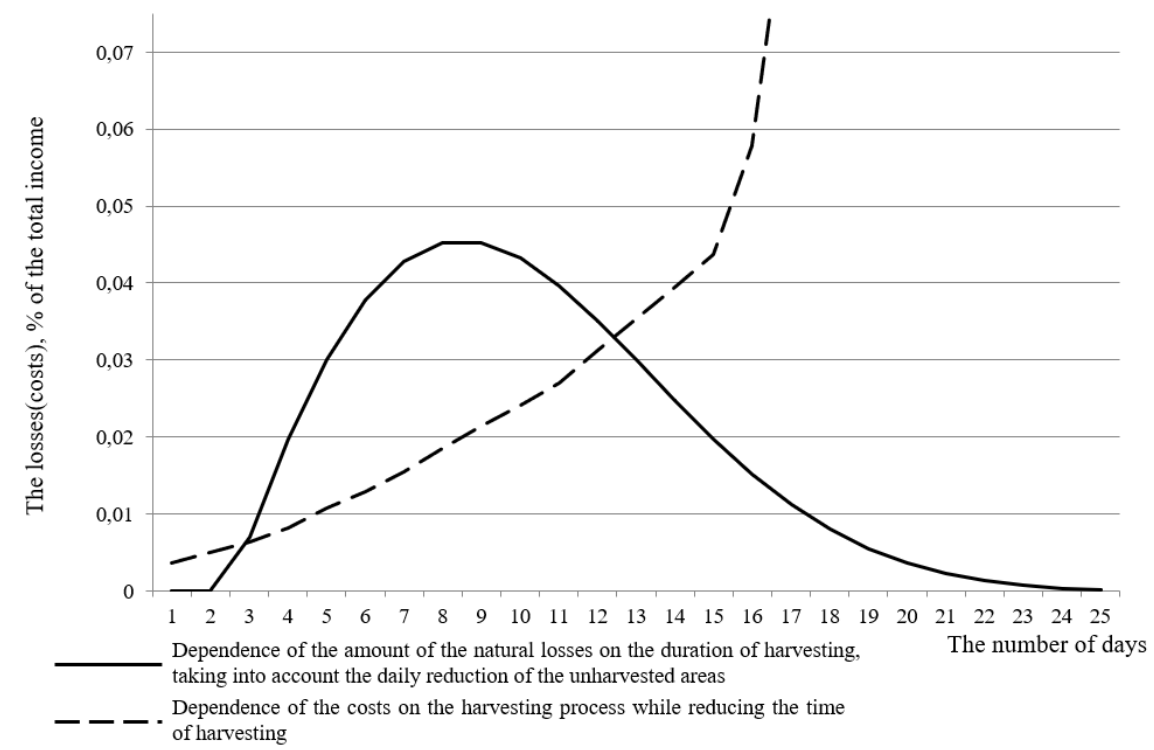

Fig. 8. The ratio of the costs associated with a decrease in the duration of harvesting, and the losses from an increase in the duration of harvesting, taking into account the daily reduction of the unharvested areas.

\section{Results and discussion}

The interim conclusions made so far only reflect the general trends in changes in the characteristics of the production processes in the plant cultivation, and obtaining adequate 
mathematical models requires additional research. However, the presented dependence allows us to say that an increase in the number of means of the mechanization is not a universal recipe for increasing the efficiency of the agricultural production.

Along with the increase in the production capacity, it is necessary to take into account the possibilities of improving the performance of the existing processes. Thus, the studies $[1-3,15]$ have shown that improving the approaches to organizing the harvesting processes will increase the efficiency of work by 40 percent, and optimizing the choice of the operating modes for the grain harvesters - by 20 percent.

Experience shows that the measurement of the single indicators characterizing the state of the production processes in the crop production is a very time-consuming task and most agricultural enterprises do not conduct it on a regular basis.

Nevertheless, these indicators are shown, taken into account and used, but it is not done in a complex, and the interaction between them is not taken into account. As a result, it is impossible to carry out a comprehensive study of the dynamics of influence and determine the effectiveness in general.

For the purpose of the analysis, it is necessary to analyze the features of various intelligent technologies and the methods of knowledge processing in order to develop the principles for the application of the intelligent control technologies in the crop cultivation.

The integrated intelligent system allows to develop methods and the self-learning prediction algorithms for managing the efficiency of the production processes in the agroindustrial complex.

\section{References}

1. V. Kataev, I. Markvo, K. Khubiian, E. Zubrilina, E3S Web of Conferences, 175, 05034 (2020) DOI:10.1051/e3sconf/202017505034

2. V. Kataev, I. Markvo, K. Khubiian, V. Dimitrov, E3S Web of Conferences, 175, 05005 (2020) DOI:10.1051/e3sconf/202017505005

3. V. Kataev, I. Markvo, K. Khubiian, E. Zubrilina, E3S Web of Conferences, 210, 05009 (2020) DOI:10.1051/e3sconf/202021005009

4. M. Saporito, A. Da Ronch, Journal of Fluids and Structures, 94, 102869 (2020) DOI:10.1016/j.jfluidstructs.2020.102869

5. A. G. Zimmer-Faust, C. A. Brown, A. Manderson, Marine Pollution Bulletin, 137, 360-369 (2018) DOI:10.1016/j.marpolbul.2018.09.028

6. T. J. Miller, C. M. Legault, Fisheries Research, 186, 109-120 (2017) DOI:10.1016/j.fishres.2016.08.002

7. W. Wang, Y. Ma, L. Fu, Y. Cui, Y. Majeed, Information Processing in Agriculture, 2020 DOI:10.1016/j.inpa.2020.11.005

8. D. Kortenbruck, H. W. Griepentrog, D. S. Paraforos, Computers and Electronics in Agriculture, 140, 227-236 (2017) DOI: 10.1016/j.compag.2017.05.039

9. G. Craessaert, J. de Baerdemaeker, B. Missotten, O. Saeys, Biosystems Engineering, 106, 103 (2010) DOI: 10.1016/j.biosystemseng.2009.12.012

10. A. Utamima, T. Reiners, A. H. Ansaripoor, Biosystems Engineering, 184, 166-180 (2019) DOI: 10.1016/j.biosystemseng.2019.06.001

11. E. Lorencowicz, J. Uziak, Agriculture and Agricultural Science Procedia, 7, 152-157 (2015), DOI: 10.1016/j.aaspro.2015.12.010

12. W. Eduardo, B. C. Tenin Su, T. G. Pera, et al., Sustainable Production and Consumption, 21, 228-238 (2020) DOI: 10.1016/j.spc.2019.09.002 
13. K. Hakala, J. Heikkinen, T. Sinkko, K. Pahkala, Biomass and Bioenergy, 95, 8-18 (2016) DOI: 10.1016/j.biombioe.2016.08.021

14. N. Dubenok, A. Mayer, Izvestia of the Lower Volga Agro-University Complex, 59, (2020) DOI: 10.32786/2071-9485-2020-03-37

15. I. Markvo, E. Zubrilina, V. Novikov, E3S Web of Conferences, 126, 00054 (2019) DOI: $10.1051 /$ e3sconf/201912600054 